\title{
EI diablo en la música: la muerte del amor en El gavilán, de Violeta Parra Lucy Oporto Valencia
}

\author{
Edición corregida y aumentada. Editorial Universidad de \\ Santiago de Chile, Santiago, 2013. 461 págs.
}

\section{Lorena Valdebenito Carrasco}

Universidad Alberto Hurtado, Santiago, Chile.

Email: lvaldebe@uahurtado.cl

\section{Aspectos formales}

El texto de la autora chilena Lucy Oporto El diablo en la música. La muerte del amor en El gavilán, de Violeta Parra publicado por Editorial Universidad de Santiago de Chile, fue presentado en el marco de la $33^{\mathrm{a}}$ Feria Internacional del Libro de Santiago el 26 de octubre de 2013. Estructuralmente el libro desarrolla su contenido del siguiente modo: inicia con un prólogo de la autora para esta segunda edición, luego se establecen unas Consideraciones Preliminares. Posteriormente se divide en dos partes. La primera se titula Antecedentes de El gavilán y fuentes del pensamiento de Violeta Parra incluyendo cuatro capítulos. La segunda parte lleva por titulo: La muerte del amor en El gavilán, que contiene seis capítulos. Luego concluye con unas Consideraciones finales. Posteriormente se incluye un apartado llamado Coda, un nutrido Apéndice y un Post Scriptum que contiene tres ensayos de la autora.

\section{Aspectos de contenido}

Oporto, a nuestro parecer, en su libro invita a participar de una profunda reflexión sobre Violeta Parra y su obra El gavilán desde cuatro ejes articuladores: la filosofía, la historia, la música y, como rama de la filosofía, la metafísica. Se hará una revisión de cada ámbito por separado y posteriormente se tratarán ciertos aspectos metodológicos del libro.

1. La filosofía. La filosofía en el libro se presenta con la cantidad justa de dientes que permiten masticar las ideas que guían el pensamiento, una aproximación a la fealdad / maldad del alma, el texto presenta como desafío la invitación a conocer sobre el por qué y las circunstancias de la muerte, una multi-muerte: la de Violeta, la del amor, la de la conciencia, la de Chile, la de todos los torturados, la de todos los masacrados, la de todos los suicidados. La muerte aquí es tratada como un arquetipo, como ima- 
gen primordial que ayuda a situar al ser humano en su condición frágil e inerme, pero también a desentrañar en torno a los vacíos del alma a través de la muerte y de todo acto de muerte.

El espesor de los planteamientos de la autora tiende a la negatividad, hacia el camino sin salida frente a la conciencia sobre la destrucción de la espiritualidad del ser humano como problema universal, pero también particularmente en Chile. Un problema sin solución para la autora, quien, desde su ventana prefigura, no una filosofía existencialista debido a que no resultaría propio establecerlo de este modo, pero sí con elementos existencialistas, cercanos a Kierkegaard. De igual modo tiende al manejo de una dialéctica negativa, acaso adorniana, estableciendo diálogos crudos, entre el sinsentido y el pesimismo, planteados en torno a un desarrollo epistemológico de duras contradicciones, al lograr una apertura en sus planteamientos filosóficos, en contraposición a un cierre; a una resolución de contrarios. Esto último, por tratarse de problemas que escapan a la esquiva lógica y sus relaciones con el hombre y la mujer, al discutir desde una visión ética el tema de los derechos humanos, la violencia, la ya citada muerte, las heridas, el homicidio y los horrores.

A contraluz, también surgen ideas sobre la belleza del alma que parten desde Violeta como figura comprendida como una mujer profunda, con una función arquetípica por cuanto representa con su vida / obra el dolor y el sufrimiento, pero también la asunción de una responsabilidad artística, más allá de la muerte. El arte de Violeta, en su más complejo sentido, es el que operaría como acto expiatorio para sanar y recuperar aquello que se pierde con la muerte. Por otra parte, la autora deja entrever la belleza del alma como una analogía presente en la figura de Violeta y sus anhelos, también los proyectos que quería concretar y los caminos que deseaba recorrer previamente a su muerte, contrastando esto con su trágico final. Entonces Oporto se pregunta: Pero en ese extremo luminoso, que contrasta desgarradoramente con su muerte violenta ¿dónde estaba la comunidad? ¿Dónde estaba la comunidad, con la que Violeta deseaba tanto comunicarse, cuando ella decidió quitarse la vida? (Oporto, 2013: 106). El sinsentido de la muerte aparece como hermanado al sinsentido de la pérdida de la capacidad de amar y el abandono.

2. La historia. La historia como recuerdo, como un recordar, del latín recordis, volver a pasar por el corazón es la historia que a nuestro juicio, intenta la autora. La historia como un recuerdo vivo que contextualiza el pasado de Chile y su relación con los actos políticos del golpe de estado de 1973, la posterior vulneración sistemática de los derechos humanos y la post-dictadura. Un tema que cada vez más se trata desde la academia, junto a nuevas perspectivas que van surgiendo en la manera de abordar estos asuntos. La que ofrece la autora se relaciona con un mal recuerdo de la historia. Un mal recuerdo no porque la memoria recuerde mal, sino porque el peso que posee este hecho se despliega con las dimensiones que soportan las de un problema ético de gran envergadura, siendo el mal un advenedizo, intruso incubado en Chile. Un país que se ha entregado a un sistema 
político-económico asfixiante y falto de ética ya que finalmente el amor, no solo como sentimiento sino que también como principio, es sacrificado para obtener réditos basados en el poder y la economía. Desde el libro, la historia se muestra tal como es, es decir, con todos los pliegues posibles -en palabras de Deleuze- en los que se ve reflejado el ser humano desde el lado de sus sombras. En este sentido, El gavilán de Violeta Parra es tratado como historia en la que se presenta un doble sentido de historicidad; por una parte, la obra se comprende de acuerdo a las circunstancias y momento en que fue concebida y, por otra parte, por su carácter simbólico de proyección futura, pues para Oporto El gavilán sería un presagio del golpe de estado de 1973, visto como un hecho sincronístico en términos de Jung.

Si bien la historia es el testimonio que evidencia lo ocurrido, no todo lo que ha ocurrido se muestra o es conocido. Para Hugo Zemelman, notable pensador chileno quien ha partido recientemente, el desafío de la historicidad se expresa en asomarse a lo desconocido (Zemelman, 2010: 363) que incluye también la visión de presente y futuro para comprender el pasado. Un pasado común que cuando es traído a la memoria, sea éste como fragmento o como totalidad, vuelve a remover el corazón para que, al menos, permita si no en esta generación, tal vez en algún futuro, un resarcimiento de los actos del pasado y su explicación.

3. La música. La música es un tipo de historia; es historia circular porque retorna el tiempo escuchado. Así, El gavilán nos trae de vuelta la música de Violeta y a Violeta, pero junto a ella, también el tiempo que gastó para que nosotros oyéramos esa música.

Los nuevos paradigmas musicológicos que invitan a comprender la música nos recuerdan que para analizarla y entenderla, ésta ya no puede abordarse a partir de un elemento solamente sonoro, entendido desde la física. Lo que logra Oporto es ampliar la perspectiva de aproximación a la obra musical logrando un análisis hermenéutico, donde obra y autor son tratados como una misma cosa, donde los tramados históricos, políticos, filosóficos y antropológicos que circundan la obra, se conciben como imprescindibles para comprender y significar a Violeta y El gavilán como pieza clave de su corpus musical.

Sobre la relación autor / obra, Oporto considera que se ha intentado: liquidar la figura misma de Violeta como referente cultural, despojando su obra de su sentido político y reflexivo, y adelgazar el espesor de ambas, convirtiéndolas en un producto de fácil asimilación para la masa juvenil de consumidores (Oporto, 2013: 29). Esta reflexión cobra sentido si pensamos que la figura de Violeta Parra se ha intentado separar de su pensamiento, de su música, quizás en un acto de despolitización dado a su contenido elaborado desde la crítica a lo social, la problemática de la marginación, pero también debido a la complejidad de sus ideas y la singularidad pletórica de su visión de mundo.

El análisis musical realizado por la autora se basa en la delimitación 
de los momentos de la obra. Ofrece una profunda interpretación de El gavilán, principalmente a partir de los dichos de la propia Violeta y diferentes datos y testimonios que rodean la obra. La construcción de sentido en la música es la última creación después de la obra creada, que aparece como una ecuación paradojal, dispuesta a ser resuelta o interpretada. Como dice Jankélévitch: La música no significa nada, por lo tanto lo significa todo (Jankélévitch, 2005: 32).

La interpretación del desarrollo musical en el libro se presenta como relato descifrable a través de la propuesta de una escucha centrada en los recursos musicales que dan sentido a la obra, y que son detallados por la autora en los siguientes elementos: los intervalos (tritono), el ritmo (cueca feroz), el tipo de rasgueo (rasgueo homicida), la emisión vocal, (voz sufrida) y el texto (filosófico: texto de persecución) basando su análisis en la teoría del chivo expiatorio de René Girard (1982). La propuesta de análisis de cada uno de estos elementos musicales permite explicar la configuración de una obra atípica o rara dentro de la música popular, como lo sostiene la autora. La figura del Diablo es clave para comprender la obra, ya que desde un análisis filosófico y musical se atreve a ensayar sobre la base de dos elementos constructivos: el símbolo y el signo. El símbolo del mal, es representado en la figura de El gavilán, como un ser perturbador, maligno, el diablo que destruye a su víctima. Por su parte el signo sonoramente descifrable se presenta en el intervalo de cuarta aumentada, o tritono (ejecución de tres tonos enteros de modo simultáneo o alternado) llamado en la época medieval como diabolus in musica presente en El gavilán y que representa, según la autora, el dolor, el sufrimiento y el mal. Su idea es, entonces establecer un vínculo entre la disonancia y el dolor tomando como referente el pensamiento de Theodor Adorno y su Filosofía de la nueva música.

4. La metafísica. En la actualidad, tras la pérdida del sujeto como figura importante para comprender el mundo y sus posibilidades de construcción desde la historia, la filosofía o la música; la metafísica resulta aún más ajena como ámbito del conocimiento -y aunque ligado a la filosofíaparece como aparte, y muy separado de los planteamientos llamados científicos, cada vez más distanciados como lo ha sido parcialmente la fe de la razón, la ciencia de la sabiduría: el viejo tema de los opuestos. Al parecer las problemáticas de la metafísica parecen no ser temas atrayentes como para ocuparse de ellos en el hoy. Aquello ocurre tal vez por el distanciamiento del ser humano de sí mismo y de los otros, tal vez por el miedo a encontrarse con sus propios estados, con sus verdaderos problemas o en términos junguianos con su propia sombra. En el Capítulo 2, agregado en esta segunda edición, la autora, a partir de conceptos propuestos y trabajados por Jung, opta por realizar un análisis de elementos o factores arquetípicos en Violeta Parra, de manera que su arte se vería manifestado en un diálogo entre su propio mundo interior y una raíz arcaica, universal, que como sostiene Oporto, en este hecho se produce una continuidad entre lo individual y colectivo, interior y exterior, subjetivo y objetivo, presente, pasado y futuro. Esto es lo propio de aquellas expresiones simbólicas 
enraizadas en el inconsciente colectivo (Oporto, 2013: 92, 93). Para sostener este análisis, realiza una revisión de textos de diferentes autores y dichos de la propia Violeta donde se exponen estos conceptos, ya sea explícita o implícitamente.

\section{Cuestiones metodológicas y la figura de Violeta Parra en el texto}

El símbolo y su significado aparece en un primer plano a través de una metodología filosófica llamada por la autora arqueología del alma, un modo de aproximarse a los estados internos del ser humano y representaciones adyacentes en diversas matrices, tramas, formas, líneas, imágenes, huellas e incluso ruinas de un pensamiento (Ibid, 45) tomando como referente el pensamiento junguiano, la concepción argumentativa de la filosofía de Miguel Orellana Benado y la interpretación simbólica y analógica de Gastón Soublette.

El texto es primicia en su aproximación metodológica por cuanto ofrece una revisión contextualizada de trabajos previos en esta misma línea del texto en cuestión, es decir, que aborden las construcciones o significaciones que fue teniendo el personaje de Violeta, hecho que puede notarse tempranamente en el ensayo de Patricio Manns Violeta Parra (1984), posteriormente en el texto Violeta Parra: la última canción de Leonidas Morales (2003) y luego en el trabajo más reciente Violeta Parra. Instantes fecundos, visiones, retazos de memoria de Jorge Montealegre (2011). En este sentido, la autora inicia un diálogo, llegando si se quiere, en algunos casos, a una interpelación hacia los autores que se han dedicado a la investigación de Violeta Parra, ya sea desde una perspectiva valorativa o despectiva de su persona. Diálogo necesario que se debería tomar como camino para lograr una comprensión y replanteamiento de cómo nos pensamos, cómo nos construimos, cómo damos sentido a nuestra realidad chilena donde convergen filosofías, músicas, sabiduría popular, mitología, ciencia y todo quehacer variopinto en un tipo de país híbrido en razón de las huellas de su pasado, pero que tal vez se ha olvidado de dialogar internamente para lograr algo de aquella resbalosa identidad o autenticidad. Según Sergio Larraín, Violeta echaba de menos ese diálogo cuando recuerda de sus palabras: ...digo las cosas y nadie me responde. Nadie me dice nada. Y yo vivo entre esta gente aquí... tengo que tener un diálogo con esta gente... ¡No hay tal diálogo!... cada uno viviendo su vida... (tambuk y Bravo, 2011: 151).

Oporto de algún modo rompe con un tratamiento de la figura de Violeta de corte más bien divulgativo, o de homenaje solamente. Nos parece que con este texto se abre una nueva perspectiva de conocer e investigar su figura, convirtiéndose quizás en el siguiente eslabón de la cadena investigativa, es decir, que se pasa del texto del homenaje, de la biografía, de la recopilación musical o la antología musical o poética, y hasta del ensayo -no obstante que éste además lo sea- a cómo se ha comprendido a 
Violeta Parra. En esta misma línea la autora desarticula toda construcción de una Violeta sexualizada post-mortem por ejemplo, o la visión simplificada, estereotipada, menospreciada o reducida de su figura.

En su segunda edición, se agregan tres capítulos (Cap. 2, Cap. 7 y Cap. 10) además la obra aumenta en la precisión de datos y en la información contenida, como igualmente se realiza un análisis más profundo de dichos apartados. Así también se han agregado tres ensayos de la autora en torno a temas relacionados con El gavilán que permiten ampliar los ámbitos del contenido del libro.

Esta obra puede resultar atractiva para quienes deseen conocer sobre los intersticios de la obra El gavilán, tras intuir que a partir del sonido se esconden suculentas ideas o que las ideas escondan lo que el sonido quiere decir por sí mismo. Y por último, para quienes deseen indagar un poco más en la explicación de su vida cortada con tal premura, la explicación de su muerte prisionera en una tumba, versos que funcionan como una autoprofecía musical enunciada por parte de Violeta. 


\section{Bibliografía}

Jankélévitch, Vladimir (2005), La música y lo inefable, [Trad. Ramón Andrés y Rosa Rius], Alfa Decay, Barcelona, España.

Oporto, Lucy (2013), El diablo en la música. La muerte del amor en El gavilán, de Violeta Parra, Editorial Universidad de Santiago de Chile, Santiago de Chile.

Stambuk, Patricia; Bravo, Patricia (2011), Violeta Parra el canto de todos, [Edición revisada, corregida y aumentada de Gracias a la vida. Violeta Parra. Testimonios], Pehuén, Santiago de Chile.

Zemelmen, Hugo (2010), “Sujeto y subjetividad: la problemática de las alternativas como construcción posible”, en Polis, N 9, Polis. Revista Latinoamericana, Santiago de Chile. 